\title{
Challenges facing the COVID-19 pandemic in Brazil: lessons from short food supply systems
}

\author{
Potira V. Preiss ${ }^{1}$ \\ Accepted: 24 April 2020 / Published online: 12 May 2020 \\ (c) Springer Nature B.V. 2020
}

We are closing the first month of quarantine in Brazil, the official numbers indicate more than 40,000 people infected and 2500 deaths by COVID-19. However, given the rationalized testing policy, specialists alert there is a high number of underreported cases, and the official numbers might account for nearly $10 \%$ of cases. We are in the deep dark and there is no indication of when we will be out of the woods.

The challenging situation began in a fragile political moment in Brazil. The Brazilian president has been completely despicable, disregarding the gravity of the situation, acting against mitigation strategies, and disseminating false news. There is no cohesive political leadership, governors and mayors are acting without a coordinated plan. Unemployment is growing faster and the population that was already in a precarious condition is becoming an easy prey. We do not know what will kill them first, hunger or COVID-19.

Overall, activities in the country are restricted to essential services, such as health care and food supply. In this field, the main protagonists are farmer families who account for about $80 \%$ of the country's food production. This group is mostly in a context of social vulnerability due to their depravation of public policies because lawmakers prioritise the production of commodities and exportation. Currently, the profile of a Brazilian family farming is aging and in poverty, making them twice as victims of COVID-19. They should be supported and protected.

Supermarkets are recognised internationally for the low prices they pay to farmers and for offering ultra-processed foods, which are less healthy. Thus, prioritizing farmers'

This article is part of the TopicalCollection: Agriculture, Food \& Covid-19.

Potira V. Preiss

potira@unisc.br

1 Graduate Program in Regional Development, University of Santa Cruz do Sul - PPGDR/UNISC, Santa Cruz do Sul, Brazil direct marketing channels is essential. Street farmers markets are the Brazilians second favorite place to buy food, and most of them remain open during the outbreak with a series of security measures in place such as: bigger distance between stands, stronger asepsis, supply of cleaning material, usage of masks and advertising how to prevent contamination. The indoor farmers markets have been suspended and in some cases the producers have organised home delivery schemes. The remaining challenge is the ability to quickly adapt to a completely different form of trading. For instance, the lack of a free e-commerce platform that could help advertise and facilitate ordering is an obstacle because it makes the job more work intensive. Besides, it takes experience to become efficient in a new trading channel.

In the case of existing Solidarity Purchasing Groups (GAS), Community Supported Agriculture (CSA) and delivery system, there is a huge explosion in demand. Some producers report twice as many orders, overloading the capacity to cope. The above systems offer a simple buying experience for consumers and a stable demand for producers that guarantees continuous income and helps with production planning. Brazilian researches on agroecological markets, GAS and CSA systems demonstrate that those channels work mostly with family farmers that produce local organic or agroecological fresh food and can be up to 400 times cheaper than the organics commercialized by supermarkets. It generates higher revenue to farmers and more accessible quality products for costumers, breaking the myth 'clean food is expensive'. New consumers and new groups of farmers experiencing those channels offer an interesting potential for widening such strategies in size and number after the quarantine period.

For those who cannot afford to buy food, the hope is also in family farming that can supply the vulnerable population with basic food-especially if the State inject emergency resources in the existing institutional programs. This is a strong demand from social movements in Brazil, however 
without action by the State yet. There are many civil society donation campaigns, but they do not meet the demand.

It is hard to set any conclusion, but some lessons have been already learned. The agroecological farmers network experience and cooperative articulations stand out of the crowd with their resilience capacity. The disruption in recent years of a series of food policies in progress in the country aggravates the situation and demonstrates that the State's role is imperative for safeguarding food producers and ensuring food security. We urgently need to reterritorialise food systems by embedding them to social needs and ecological process. Consumers have a key role to play in this transformation by supporting economically and politically the type of food systems they want to foster. Finally, despite all, this crisis may be the wakeup call we all need to redirect society priorities and encourage us to endeavor the necessary changes.

Publisher's Note Springer Nature remains neutral with regard to jurisdictional claims in published maps and institutional affiliations.

Potira V. Preiss Post-Doctoral Researcher at Graduate Program in Regional Development at University of Santa Cruz do Sul - PPGDR/ UNISC, PNPD/CAPES Fellow and researcher at Group of Studies and Research in Agriculture, Food and Development - GEPAD/UFRGS. 